\title{
XXXIII. Greenockit, Wurtzit und Smithsonit von der Grube Lüderich bei Bensberg.
}

\author{
Von
}

\author{
I. Souhour in Aachen.
}

(Aus dem mineralogischen Institut der königl. technischen Hochschule.)

Bei einem Besuche der Zinkerzgrube Lüderich bei Bensberg, welche in weiteren Kreisen durch den verhältnissmässig bohen Gallitmgehalt ihrer Zinkblende bekannt geworden ist, fiel mir auf einer Erzhalde am Mundloche des »tiefen Luderichstollens « ein bisher in dorliger Gegend noch nicht beobachtetes Mineral von canariengelber bis zeisiggriner Farbe auf. Das Haufwerk der Halde stammte von der erst seit kurzem in Abbau begriffenen nơrdlichen Fortsetzung der »nördlichen Lagerstätte ". Das Mineral, welches sich bei der von Herrn $\mathrm{Th}$ a d dé eff vorgenommenen chemischen Untersuchung als Greenockit erwies, bildet erdige Anfluge auf den Kluften, welche die Gangmasse (Thonschiefer, Grauwacke und derbe, dunkelgefärbte Blende) durchziehen.

Auf denselben Kluften kommen neben Kalkspath-, Quarz- und Blendekrystallen mit der Lupe schwer erkennbare, aber auf chemischem Wege unzweifelhaft als Wurtzit und Smithsonit bestimmte Krystalle vor.

Kratzt man die Wurtzitkrystalle ab und beobachtet dieselben unter dem Mikroskope, so erkennt man unter vielen unregelmässig geformten Bruchstücken lang trapezförmige, deutlich hemimorphe Gestalten mit zwei gleichen gegenuberliegenden slumpfen Winkeln und zwei ungleichen Spitzen.

Die mit Hulfe des Fadenkreuzes und des drehbaren Tischchens vorgenommene Messung ergab für den einen spitzen Winkel 770_780. Der andere spitze Winkel lag bei einer Gruppe von Krystallen zwischen $23^{\circ}$ und 28,5 , bei einer anderen zwischen $31^{\circ}$ und $36^{\circ}$.

Die gemessenen Winkel können wohl nur als Winkel von Pyramidenkanten aufgefasst werden. 
550 L. Souheur. Greenockit, Wurtzit und Smilhsonil von der Grube Lüderich。

Die Berechnung ergiebt für diese Winkel der Pyramiden $\{50 \overline{5} 1\} 27030^{\prime}$, $\{40 \overline{4} 1\} 34^{0} 1^{\prime},\{30 \overline{3} 2\} 7^{\circ} 24^{\prime}$, welche Werthe mit den gemessenen in Anbetracht der primitiven Mittel der Messung ziemlich gut ubereinstimmen. Die genannten Pyramiden sind am Wurtzit bisher nicht beobachtet; die beiden ersten kennt man am Greenockit.

Die sammetartig glänzenden, durchscheinenden, schmutziggelb bis dunkelgrun gefärbten Smithsonitkrystalle zeigen Prisma und Basis und bilden infolge des Vorherrschens der letzteren sechsseitige Plättchen, ein Habitus, der anscheinend bisher nicht beobachtet ist. Das Prisma charakterisirt sich durch die an ihm wahrnehmbare, durch das Auftreten eines Rhomboëders veranlasste, schräge Streifung als solches zweiter Stellung.

Der Neigungswinkel der Streifen zur Kante [11 20.0001$]$, welcher unter dem Mikroskope gemessen wurde, beträgt im Mittel $34^{\circ}$ (Grenzwerthe $\left.33^{0}-37^{\circ}\right)$ und entspricht ziemlich genau dem Rhomboëder $\{40 \overline{4} 5\}$ (berechnet $\left.33^{0} 54^{\prime}\right)$. 